\title{
Health risk assessments of heavy metal exposure via consumption of marine mussels collected from anthropogenic sites
}

\begin{abstract}
A total of 40 marine mussel Perna viridis populations collected (2002ï 2009) from 20 geographical sites located in two busy shipping lanes namely the Straits of Malacca (10 sites; 16 populations) and the Straits of Johore ( 8 sites; 21 populations) and three populations ( 2 sites) on the east coast of Peninsular Malaysia, was determined for $\mathrm{Cd}, \mathrm{Cu}, \mathrm{Fe}, \mathrm{Ni}, \mathrm{Pb}$ and $\mathrm{Zn}$ concentrations. In comparison with the maximum permissible limits (MPLs) set by existing food safety guidelines, all metal concentrations found in all the mussel populations were lower than the prescribed MPLs. In terms of the provisional tolerable weekly intake prescribed by the Joint FAO/WHO Expert Committee on Food Additives (JECFA) and oral reference doses (ORDs) by the USEPA, all the studied metals (except for $\mathrm{Pb}$ ) were unlikely to become the limiting factors or unlikely to pose a risk for the consumption of the mussel populations. The estimated daily intake (EDI) for average level mussel (ALM) and high level mussel (HLM) consumers of mussels was found to be lower than the ORD guidelines for Cd, $\mathrm{Cu}, \mathrm{Fe}, \mathrm{Ni}$ and $\mathrm{Zn}$. Furthermore, the target hazard quotient (THQ) was found to be less than 1 for ALM consumers but higher than 1 for HLM consumers in some sites. Therefore, there were no potential human health risks to the ALM consumers of the mussels. However, for $\mathrm{Pb}$ THQ values, the $\mathrm{Pb}$ levels in some mussel populations could create a health risk problem. Present results indicate that the consumption amounts of mussels should be limited for minimizing potential health risks of heavy metals to the HLM consumers.
\end{abstract}

Keyword: Health risk; Target hazard quotient; Mussels; Biomonitoring; Heavy metals 